УДК 821

\title{
М.Е. Крошнева
}

\section{ПРЕДПРИЯТИЕ, «ИЗЯЩНО ИЗДАЮЩЕЕ ДОСТОЙНЫЕ КНИГИ...»}

В работе исследуются фактические особенности историко-литературного контекста книжной культуры в Финляндии на русском языке. На примере работы издательства «Библион» (1919-1921 гг.) приводятся сведения, способствующие изучению аспектов издательской деятельности иностранных организаций, подданных Швеции и Финляндии, способствующие появлению книг художественной литературы многих русских авторов, самыми известными из которых в этот период являлись Леонид Андреев и Александр Куприн. Для более полного представления вопроса о развитии русского книгоиздания между 1919-м и 1921-м гг. необходимо знать не только тенденции изданий общегосударственного масштаба, видеть особенности развития книгоиздания регионов, но и учитывать специфику издательской деятельность русского зарубежья.

Результаты работы могут использоваться в преподавании учебных курсов по литературе и культуре русского зарубежья, истории русской литературы первой трети XX столетия, исследованиях литературы регионов, при уточнении и дополнении биобиблиографий, библиографий, каталогов, энциклопедий, других изданий и публикаций русской литературы за рубежом.

Ключевые слова: издательское дело, русское зарубежье, русская литература.

DOI: $10.35634 / 2412-9534-2021-31-3-564-570$

В Финляндии в начале 1920-х гг. функционировало несколько издательских предприятий, занимающихся выпуском в свет русской литературы и периодики, среди них было два крупных издательства - «Библион» и «Фундамент», а также десяток небольших типографий, владельцами которых являлись отделы русских эмигрантских газет, журналов и разных общественных объединений («Русская жизнь», «Новая русская жизнь», «Русские вести», «Известия Гельсингфорсского совета депутатов», «Гельсингфорсский кружок народных писателей», «Финское литературное общество», «Шведское литературное общество»). В небольшом перечне организаций внимание автора работы привлекает судьба «Библиона», выпустившего в свет, по данным «Библиографии русской литературы, изданной в Финляндии 1813-1971», не более 8 наименований изданий [4, с. 6-9]. Много это или мало, судить сложно. Однако историческая, социально-культурная ценность предприятия, заключающаяся в образцовой возможности, по мнению писателя И. А. Бунина, «изящно» публиковать «достойные книги» [6, с. 43] на русском языке в непростое для Финляндии и России время, когда налаживание политических и экономических взаимоотношений, культурных и торговых связей было, практически, невозможно, дает право исследовать литературные и издательские связи русского зарубежья в Финляндии 1919-1921 гг.

Самими громкими среди публикаций издательства были произведения крупного русского писателя Леонида Андреева, последние годы жизни которого прошли в Финляндии. Вдова писателя, Анна Андреева, заключила выгодный договор на издание посмертных произведений мужа: роман «Дневник Сатаны» (объем 277 страниц с иллюстрациями) и повесть «Ночной разговор» (объем 93 страницы печатного текста) общим тиражом более 20 тысяч экземпляров; и «Полное собрание сочинений, вышедших после 1911 года (8 томов)», тиражом 10 тысяч экземпляров [4, с. 9].

Годом ранее «Библион» подготовил и выпустил в свет произведения Александра Куприна, проживавшего в то время в Гельсингфорсе и подрабатывавшего в эмигрантских газетах и журналах, сборник рассказов «Звезда Соломона» (объем 160 страниц тиражом 5 тысяч экземпляров из 10 тысяч запланированных). Основу сборника составили рассказы, три из которых были опубликованы еще до 1918 г. в русских журналах «Земля» и «Пробуждение», четыре других - в эмигрантской газете «Новая русская жизнь». В сборнике Куприна произведения подверглись некоторым изменениям и редакторским правкам, располагались в следующем порядке: «Звезда Соломона» (ранее известное под названием «Каждое желание», 1917 г.), «Анафема» (1913 г.), «Беглецы» (также известное под названием «Храбрые беглецы», 1918 г.), «Царский писарь» (1917 г.), «По ту сторону» (даты выхода отсутствуют), «Лимонная корка» (1920 г.), «Пегие лошади» (1920 г.). За публикацию рассказов автор получил гонорар 25 тысяч финских марок. 
В рекламных объявлениях издательства в качестве вышедшего в свет был указан поэтический сборник «Русская лирика за последние 20 лет (Антология). Символизм, футуризм, революционный период» $[4$, c. 48$]$. Из русских изданий в указанный период в свет вышли также поэтический сборник Владимира Белевича «Родные стихи» (объемом 280 страниц печатного текста тиражом 1200 экземпляров) и брошюра Александра Бобрика «Немного математики в теории словесности» (без указания издательства и наполовину напечатанная за счет средств автора).

«Библион» публиковал книги иностранных авторов на русском языке: роман финского писателя Иоганнеса Линнанкоски (1869-1913) «Огненно-красный цветок» (с иллюстрациями, общим объемом 311 страниц тиражом 3,5 тысячи экземпляров) $)^{1}$; сборник новелл шведского писателя Рунара Шильдта «Очарованный лес».

Истоки издательства «Библион» корнями уходят в знаменитое финно-шведское издательство в Хельсинки «Шильдц» («Schildts»), основанное в 1913 г. молодым предпринимателем Хольгером Шильдтом (Holger Schildt) (1889-1964) ${ }^{2}$ и его филиал «Хольгер Шильдц форлагсактиболаг» («Holger Schildts forlagsaktiebolag»), изначально представляющий собою издательский дом, специализировавшийся на выпуске шведской литературы.

20 ноября 1919 г. бизнес Х. Шильдта был зарегистрирован как государственное предприятие «Библион», специализирующееся в книгоиздании и печатании. Совет директоров издательства состоял из Шильдта, а также менеджера Сигурда Клокарса (Sigurd Klocars) (1892-1951), офис-менеджера Гуннара Сёдерстрёма (Gunnar Soderstrom) (1893-1963) и журналиста Хьялмара Даля (Hjalmara Dahl) (1891-1960). Шильдт и Клокарс обеспечивали основной капитал кампании по 249 акций каждый, в то время как Сёдерстрём и Даль держали по 1 акции. Фирма владела капиталом 250 тысяч финских марок [6, с. 3-4].

Первый год работы организации был посвящен планированию деятельности и технической подготовке. Цель предпринятого проекта - обеспечить огромный русский книжный рынок в Европе и Америке качественной литературой. Заявленная книгоиздательская сфера была широкой: «Библион» хотел издавать русскую классическую и современную художественную литературу, переводы скандинавской литературы, научные работы и учебники.

Шильдт-издатель был известен русской интеллигенции. Куприн знал его задолго до выхода книги «Звезда Соломона», подготовленной «Библион». В 1915 и 1919 гг. благодаря первоклассному переводу Х. Даля произведений Куприна «Яма» и «Гранатовый браслет» Шильдт издал книги русского писателя на шведском.

Конкретизируя личность Даля, входившего в совет директоров дома «Библион», отметим важную деталь. С 9 апреля 1920 г. Даль являлся заместителем управляющего Г. Сёдерстрёма и, по мнению исследователя Б. Хеллмана, был движущей силой издательства. Совмещая прекрасные знания русского языка с истинным интересом к русской литературе, Даль зарекомендовал себя как мастер в области перевода - ему не было равных ни в Финляндии, ни в Швеции. В статье «Biblion. A Russian Publishing House in Finland» Хеллман сообщает следующее: «At the board meeting on April 9, 1920 Gunnar Soderstrom was elected manager with Hjalmar Dahl as vice manager /.../ The driving force behind Biblion was Hjalmar Dahl, who combined a good knowledge of Russian with a genuine interest in Russian literature /.../ Dahl had also published his first translation of Russian literature, a field in which he was to become one of the leading names in Finland and in Sweden» [6, c. 3].

Кратко остановимся на вопросе о публикации книг Андреева. «Библион» сделал предложение о сотрудничестве Анне Андреевой через Федора Фальковского - персону, сыгравшую важную роль в истории существования издательского дома ${ }^{3}$. Как знакомый семьи Андреева Фальковский был лично

\footnotetext{
${ }^{1}$ Произведение И. Линнанкоски имело международный успех, ранее его публиковали на эстонском (1906 г.), польском (1908 г.), немецком (1909 г.), английском (1920 г.). Русский перевод «Огненно-красного цветка» первоначально был опубликован в Москве в 1912 г., его переводчиком был А. Богенгардт (A. Bogengardt), писавший под псевдонимом А.Я. Сипельгас (А. Ja. Sipelgas).

2 За несколько лет работы издателем Шильдт сделал так, что его предприятие успешно конкурировало с «Soderctrom \& Со» («Сёдерстрём \& Ко»), самым крупным шведским издательским домом в Финляндии. К 1919 г. Шильдт переехал из Порвоо в Хельсинки и был готов к широкомасштабной издательской деятельности, в том числе изданию книг на русском языке.

${ }^{3}$ Федор Фальковский (1874-1942) - писатель, драматург. С 1910 г. был знаком с Андреевым по работе в Новом драматическом театре в Петербурге.
} 
заинтересован в получении положительного ответа, намеревался стать редактором неоконченной рукописи писателя «Дневник Сатаны» и других его изданий. 9 сентября 1920 г. был подписан контракт между вдовой и издательством, а с 1 марта 1921 г. книга «Дневник Сатаны» поступила в продажу.

По сообщению Хеллмана, сама Андреева была удовлетворена изданием, поскольку увидела в нем книгу замечательно оформленную, а фотографии мужа - удачными. Книга сопровождалась послесловием «От издательского дома», написанным, скорее всего, Фальковским. Его мысль сводилась, примерно, к следующему: «Возможно, намерения писателя были шире, чем рукопись, которую он оставил после себя; возможно, написанный текст требовал доработки, необходимость этого чувствовалась в некоторых местах. Издательский дом сделал точные копии рукописи, которые позволят читателю воссоздать в своем воображении одного из самых интересных пророков мировой катастрофы, которого писатель унес с собою в могилу». Обратимся к самой статье исследователя: «Anna Andreeva had every reason to be satisfied with the publication: she found the book beautiful and the attached photograph of Andreev agreeable /.../ The book was also provided with an afterword, signed "From the publishing house" and probably written by Falkovskij: It is possible that the intention of the writer was broader than the manuscript he left after him; it is also possible that the written text would have been worked over; the need for this is felt at places. The publishing house has made a precise copy of the manuscript, letting the reader recreate in his imagination what one of the most interesting seers of the world catastrophe took with him to the grave» [6, c. 8-9].

По мнению литературных критиков эмиграции, публикация произведения Андреева не получила больших рецензий и критических отзывов [4], хотя быстро последовали ее переводы на английский, немецкий, итальянский языки. В том же году «Дневник Сатаны» был переведен на шведский язык известным финно-шведским писателем Ярлом Хеммиром (Jarl Hemmer) и выпущен в свет Шильдтом в Финляндии и Бонниерсом (Bonniers) в Швеции. Отдельные экземпляры издания появились в Советской России, а спустя год произведение было напечатано в сокращенном виде в Москве. Один экземпляр этой книги хранится в Ленинской библиотеке в Москве [1].

Второй том посмертных работ Андреева («Ночной разговор») был издан в конце апреля 1921 г. и оказался практически незамеченным для русского эмигрантского сообщества.

Публикация книг известного русского писателя была изначально запланирована «Библион» как скромная «прелюдия» к более крупному проекту: подготовке и изданию собрания сочинений из восьми томов, включающего поздние работы художника, в том числе «Рассказ о семи повешенных» и антибольшевистский памфлет «S.O.S.». В статье о работе издательства исследователь Бен Хеллман сообщает об этом намерении следующее: «The publication of his posthumous works was originally planned to be only a modest prelude to a much biggest project, an eight-volume collection of late works, ranging from the well-known novel Rasskaz o semi povesennyx to the anti-Bolshevic pamphlet $\underline{\text { S.O.S.» }}$ (подчеркнуто - Б. Х.) [6, с. 14].

Вскоре после выхода в свет основных четырех книг, описанных нами выше, «Библион» начал рекламную кампанию в центрах русского зарубежья. Издательство установило контакт с наиболее важными эмигрантскими газетами и журналами в Берлине («Руль», «Русская книга», «Голос России»), Париже («Последние новости»), Праге («Воля России»). Самым важным из этого списка был ежемесячный журнал «Русская книга», первый номер которого был издан в Берлине в январе 1921 г. Среди достоинств журнала можно выделить его благополучный отход от политической жизни и умение сосредоточить внимание аудитории на произведениях русской литературы зарубежья. Под руководством главного редактора А.С. Ященко «Русская книга» вскоре явилась центральным информационным органом издательских домов в эмиграции.

Частные лица из Финляндии, Эстонии, Норвегии, Дании, Швейцарии, Франции, Чехословакии, Польши, Югославии, Италии, Румынии, Турции подавали заявки на приобретение книг и запрашивали каталоги продукции «Библион». Ввиду тяжелого материального положения русского эмигрантского сообщества в Европе, многие заказы представлялись в форме просьбы бесплатно прислать экземпляры изданных книг. В частности, известная библиотека Ивана Тургенева в Париже писала, что с 1914 г. десятки тысяч русских солдат и военнопленных опустошили ее, и теперь у нее нет средств на приобретение новых книг. Союз русских студентов в Варне также просил «Библион» выслать несколько изданий для бедной русской молодежи в Болгарии. Русские воспитанники в лагере Вайнберг (Weinbergslager) в Вунсдорфе заказывали изданные книги для своего округа с целью социальнополитического образования эмигрантов. 
Заказы на покупку книг приходили из книжных магазинов и импортирующих фирм Таллинна, Берлина, Парижа, Праги, Лондона, Рима, Софии, Белграда, Кишинева, Константинополя, Нью-Йорка. В перечисленных городах торговые взаимоотношения с издательством поддерживались посредством агентов: Фердинанда Вассермана (Ferdinand Wasserman) в Таллинне, Михаила Альтера (Dr. Michael Alter) в Берлине, «Я. Поволоцки \& Ko» (J. Povolozky \& Cie) и Русско-Французской библиотеки в Париже, «Нашей речи» в Праге, «Родного слова» и «Русской исторической книги» в Лондоне, Русской библиотеки «Слово» в Риме, Русско-болгарской книготорговли в Софии, «Русской Мысли» в Белграде, Гласул Тарии (Glasul Tarii) и К. Счехтера (K. Scnechter) в Кишиневе, «Русской Мысли» и Русской библиотеки в Константинополе, Макса Н. Майсела (Max. N. Maisel) в Нью-Йорке [6, с. 33].

Если «Библион» получал относительно маленькие заказы, по 10-25 экземпляров, то ими занимался магазин Академической Библиотеки в Гельсингфорсе. «Библион» брал на себя только крупные продажи, предоставляя при этом $30 \%$ скидку при приобретении более 50 экземпляров издания. В основном издательство приветствовало продажи на комиссионной основе за наличные деньги. По мере того, как коммерческие дела улучшались, стало ясно, что вести торговлю с Европой, Америкой и Дальним Востоком только из Хельсинки невозможно. Вскоре «Библион» принял выгодное предложение от Генриха Сакса (Heirich Sachs), владельца книжного магазина «Москва» в Берлине, имеющего многочисленные торговые связи по всему миру. Для начала Сакс был готов заказать 100 экземпляров четырех книг дома «Библион» на комиссионной основе с максимальными скидками.

В начале 1920 г. магазин «Москва» был основан московским эмигрантом Г. Саксом. В следующем году им был открыт филиал магазина в Нью-Йорке. К тому времени Сакс, являясь торговым представителем многих эмигрантских издательств, хотел стать агентом «Библион» в Европе (исключая страны Скандинавии, Балтики, а также Англию и Францию), Америке и на Дальнем Востоке. Условия договора были такими, что каждый третий месяц Сакс должен был сдавать отчет об объеме продаж и руководить рекламной кампанией книг «Библион». В свою очередь торговец-эмигрант получал максимальную скидку 40 \% на приобретение всех книг. С июля 1921 г. вся коммерческая корреспонденция, заказы менее 50 экземпляров, адресованные дому «Библион», переправлялись Саксу в Берлин.

В странах Великобритании и Франции агентов издательство не имело. Скандинавское представительство в Копенгагене, очевидно, было возглавлено Михаилом Пановко. В Эстонии интересы издательского дома русской литературы представлял В.Ф. Аусберг, в Латвии - Александр Сильм. «Тһе Biblion archive does not reveal who its agents were in Great Britain and France. The Scandinavian agency was apparently given to Mixail Panovko in Copenhagen, an acquaintance of Jacobsson /.../ In Estonia the interest of Библион were taken care of by V.F. Ausberg (Reval), while Aleksandr Silm was their agent in Latvia (Riga)» 6 , c. 14].

После того, как издательство опубликовало книги Андреева и Куприна, оно сделало себе имя в русских эмигрантских сообществах посредством рекламы в основных газетах и журналах, а также учредило сеть агентств, охвативших, практически, весь мир, оно продолжило планирование публикаций на следующий год. В рекламных компаниях того времени «Библион» упоминал пять новых названий будущих книг, об одном из которых уже шла речь в нашей работе: «Полное собрание сочинений, вышедших после 1911 года» Л. Андреева. Два других названия были заявлены в рубрике «Готовятся к печати»: «Очарованный лес», под которым стояла книга, служившая переводом сборника рассказов финно-шведского писателя Рунара Шильдта (Runar Schildt) ${ }^{1}$; и «Русская лирика за последние 20 лет», том, представляющий собою антологию произведений символистов, футуристов и поэтовреволюционеров ${ }^{2}$.

В рекламах «Библион» в качестве запланированных к публикации были упомянуты также два тома финно-шведского лингвиста, этнографа, политика Каи Доннера (Kai Donnera) (1888-1935) «Среди самоедов в Сибири» (Гельсингфорс, 1915), ставших популярным научным описанием быта и религии остяков-самоедов, и «Сибирские рассказы» (Гельсингфорс, 1919), являющиеся собранием очерков, основанных на личном опыте автора во время путешествий по северу России.

\footnotetext{
${ }^{1}$ Рунар Шильдт (1888-1925) - старший брат издателя. В то время он работал в «Библион» специалистом по литературе. Сборник рассказов «Очарованный лес» считался удачным, был опубликован в Швеции в 1920 г.

${ }^{2}$ Сборник стихов редактировал Виктор Игельштрём (Viktor Igelstrom) (1887-?), сын библиотекаря Университета г. Хельсинки Андрея Игельштрёма. По версии Хеллмана, позже редактор эмигрировал в Россию, где в 1923 г. опубликовал книгу «Очерки о современной Финляндии».
} 
Кроме заявленных проектов, издательство объявляло о расширении круга литературных интересов. Помимо русской классической, современной художественной литературы, переводов скандинавской литературы, научных работ, «Библион» намеревался издавать серию брошюр, посвященных различным областям сельского хозяйства: животноводству, садоводству, разведению крупного рогатого скота, птиц, приспособлению к условиям климатической полосы, а также многочисленные руководства по ремонту и эксплуатации сельскохозяйственных машин и инструментов. В научной статье Хеллман так писал о способности русской эмиграции принимать новые неожиданные решения в сфере своей деятельности: «Biblion also announced its plans to broaden its publication profile. Besides fiction it intended to publish "a whole series of brochures about different fields of agriculture, like animal husbandry, gardening, cattle-breeding, bird-breeding, adapted to the temporate climatic zone, and also guides about the repair and operation of agriculture machines and tools /... This might seem a bit surprising, but we must keep in mind that for many Russians the emigration meant the acceptance of new, unexpected professions» [6, c. 14].

«Библион» получал выгодные предложения публиковать произведения выдающихся современных русских писателей Ивана Бунина и Константина Бальмонта, широко издающихся с начала двадцатых годов прошлого столетия в центрах русской эмиграции - Париже, Берлине, Таллинне, Стокгольме, Нью-Йорке.

Бунин знал о существовании «Библион» и рекомендовал его своему коллеге Бальмонту как «издательство, изящно издающее достойные книги». Вскоре Бальмонт обратился в издательский дом - написал в письме, что он является давним страстным поклонником эпоса «Калевала» и ему было бы приятно опубликовать свои произведения в Финляндии. Он предложил издать три книги, предоставив издательству право выбора: сборник лирики «Серебряные реки» объемом 10-12 печатных листов, нигде не выходивший в свет отдельным изданием; «Край Осириса. Египетские очерки» объемом 20 листов малого формата, единожды изданные в Москве перед войной (по словам писателя, это его основная работа по Египтологии); критический этюд «Поэзия как волшебство. Рассуждения о музыкальной основе поэтического творчества» объемом 93 страницы, однажды изданный в Москве, в 1916-м г., принятый читателями с большим успехом, распроданный быстрыми темпами, в течение трех месяцев. Окончательное решение издательского дома было отложено на ближайшее будущее [6, с. 43].

В корреспонденции дома «Библион» упоминались имена В. Ропшина (V. Ropsin), автора известного романа о русских террористах «Конь бледный» $(1908)^{1}$, и других русских эмигрантов: З. Г. Ашкиназы, А. И. Вознесенского, Н. С. Дорохова, В. А. Евреинова, В. Владимирского, А. Бобрика, В. Белевича. Поступали следующие предложения переводов художественной литературы: Алексис Киви (Aleksis Kivi) «Зайтсеман вельеста» («Seitseman veljesta»), Й. Л. Рунеберг (J. L. Runeberg) «Фенрик Стальс Зегнер» («Fanrik Stals Sanger»), «Лиришес Интермеццо» («Lyrisches Intermezzo») из издания Генриха Гейне «Книга Песен» («Buch der Lieder») (6, с. 18-20).

Летом 1921 г. издательский дом русской литературы «Библион» подошел к напряженной точке существования. Основная проблема заключалась в дороговизне его книг: цены на продукцию превосходили цены немецких издательств в четыре-пять раз. Финны объясняли стоимость книг высоким качеством бумаги, богатством обложки. Кроме того, с 1919 г. происходило постепенное географическое сосредоточение центров русской эмиграции в Берлине и Париже и мало-помалу русская культурная деятельность за пределами этих европейских столиц приходила в упадок: число эмигрантских провинциальных газет падало, а издатели, работающие за пределами Германии и Франции, сталкивались с большими трудностями. В конце 1921 г. «Библион» не мог соперничать с издательствами «Слово» в Берлине, «Русская земля» в Париже, находившимися в лучшем экономическом положении в отношении с писателями. «Библион» искал собственную нишу в мировой экономике, завязывал отношения с издательствами «Колос» и «Госиздат», намеревался устроить торговые отношения с Советской Россией через Сергея Якобсона (1883-1955) и Зиновия Гржебина (1877-1929), желал сконцентрироваться на переводах финской литературы. Однако эти направления деятельности не принесли плодов.

\footnotetext{
${ }^{1}$ В. Ропшин - псевдоним Б.В. Савинкова (1879-1925), общественно-политического деятеля, писателя, члена ЦК партии эсеров, руководителя Боевой организации. С 1911 г. в эмиграции, вернулся в Россию в 1917 г., комиссар Временного правительства при Ставке главковерха (апрель-июнь 1917 г.), управляющий военным министерством (июль-август 1917 г.), организатор московского Союза защиты родины и свободы (1918 г.). В октябре 1918 г. уехал в Париж, член парижского Русского политического совещания. С 1919 г. в Варшаве, председатель Русского политического комитета, с июня 1921 г. организатор и председатель Народного союза защиты родины и свободы. В августе 1924 г. нелегально перешел польско-советскую границу. Арестован в Минске органами ОГПУ. Погиб в заключении.
} 
Упоминание личности 3. Гржебина, который еще до революции в России сумел зарекомендовать себя как талантливый и успешный издатель, дает право в двух словах охарактеризовать его деятельность около финских организаций в то время, в том числе и вокруг «Библион». Гржебин пытался организовать в Финляндии выход книг на русском языке и найти здесь надежных поставщиков бумаги для Советской Республики. Сначала в качестве председателя Общества социалистической печати при ВЦИК Совета рабочих и солдатских депутатов, затем уполномоченного Комиссариата торговли и промышленности по закупке бумаги, он проводил приобретение бумаги большими партиями, покупал ротационные и наборные машины для газет «Единство», «Солдатская правда», «Новая жизнь» и других издающих организаций. Как издатель он лично общался со многими авторами и заключал договоры на публикации их произведений (например, с Д. Мережковским, 3. Гиппиус) [2]. Одно время Гржебин намеревался опубликовать альманах «1921», авторами произведений которого являлись советские молодые писатели и поэты группы «Серапионовы братья». Но после того, как «Библион» подтвердил, что материалы альманаха находится в Гельсингфорсе и переданы книгоиздательству для публикации, Гржебин отступил от этого решения. Однако альманах «1921» так и не был издан в то время. «Весной и летом 1921 года издательство получило разные предложения из Советской России, но, пока у него не было своего постоянного уполномоченного представителя в Петрограде, решило не спешить с ответами. К несчастью, старания «Библиона» натолкнулись на визовые проблемы, и одновременно советской стороне стало ясно, что предлагаемые финские условия невыгодны, особенно в сравнении с немецкими. Интерес к «Библиону» падал, и все проекты издательства пришлось временно отложить, пока не выяснится экономическое положение» [5]. Спустя 90 лет сборник произведений «Серапионовых братьев» увидел свет в России, в издательстве К. Тублина (Санкт-Петербург).

Используя многочисленные возможности удержаться издательство «Библион» искало пути существования, но высокие цены делали его неконкурентоспособным в сложившейся ситуации. Кроме того, издательство покинули перспективные сотрудники: Якобссон ушел из «Библион» первого октября 1921 г. и сделал карьеру владельца книжного магазина, Даль - в начале 1922 г., посвятил себя переводческой деятельности.

Когда дальнейшая судьба издательского дома была решена, перед Сёдерстрёмом возникла еще одна проблема: как спасти изданные книги от забвения? 3 апреля 1922 г. он написал Культурному Атташе при Финском посольстве в Берлине Йохансу Оквисту (Johannes Ohgvist) письмо, в котором обрисовал деятельность и настоящее положение издательства. Здесь же Оквисту был обещан немалый процент в случае, если он похлопочет о продаже имущества «Библион» русскому издательскому дому в Берлине. Из переписки Оквиста и Сёдерстрёмома можно понять, насколько велик был ассортимент продукции на момент ликвидации издательства: «Звезда Соломона» - 3500 экземпляров, «Огненно-красный цветок» - 2900 экземпляров, «Дневник Сатаны» - 1000 экземпляров, «Ночной разговор» - 1400 экземпляров, «Родные стихи» - 800 экземпляров.

Оквист сотрудничал с книжным магазином «Логос», который был связан с издательством «Слово». Уже в середине июня Культурный Атташе сообщил Сёдерстрёму, что переговоры с директором «Слова» Россом (Ross) прошли успешно. «Слово» было готово купить книги дома русской литературы «Библион» за 420000 немецких марок, $10 \%$ от которых должен был получить Оквист. В конце апреля книги отправили в Берлин, и две недели спустя деньги были перечислены издательству через Немецкий Банк. Формально «Библион» был ликвидирован только через два года. 19 августа 1924 г. Сёдерстрём сообщил в Торговый реестр, что «Библион» как издательский дом прекратил функционировать в конце 1921 г.

Книги «Библиона» сохранились до наших дней. Раритетные, с плотными тяжелыми страницами, со следами времени, собранные темно-коричневыми, черными кожаными, тканевыми переплетами эпохи, с золотым тиснением по корешкам и на обложках, с образцовой типографикой текста, они постепенно пополнили частные коллекции библиофилов-любителей и профессиональные собрания редких книг российских и иностранных библиотек. Эти тома составили достойную память о профессионалах-издателях литературы русского зарубежья и издательстве «Библион».

\section{СПИСОК ИСТОЧНИКОВ И ЛИТЕРАТУРЫ}

1. Андреев Л.Н. Дневник Сатаны // Костры. М.: Госиздат. 1922. Кн. 1: (в сокращ).

2. Диннерштейн Е.А. К вопросу о репутации издателя 3. Гржебина. URL: https://magazines.gorky.media/nlo/ 2010/6/k-voprosu-o-reputaczii-izdatelya-z-grzhebina.html (дата обращения: 10.07.20) 
3. Фальковский Ф. Дневник Сатаны Леонида Андреева // Путь. 1921. 8 марта. С. 2-3; Тукалевский В. Леонид Андреев. Дневник Сатаны // Русская книга. 1921. №3. С. 21.

4. Хеллман Б., Челлберг Ю. Библиография русской литературы, изданной в Финляндии 1813-1971. Helsinki ylohiston kirjasto. Helsinki, 1988.

5. Хеллман Б. «Мы - Серапионовы братья» // Серапионовы братья. 1921: альманах. СПб.: Издательство К. Тублина. 75 с. [Электронный ресурс]. URL: https://litlife.club/books/260747/read?page=3 (дата обращения: 10.07.20).

6. Hellman B. Biblion. A Russian Publishing House in Finland // Studia Slavica Finlandensia. Helsinki. 1985. II. S. 1-48.

Поступила в редакцию 14.07.2020

Крошнева Марина Евгеньевна, кандидат филологических наук, доцент

кафедры филологии, медиатехнологий и графического дизайна,

ФГБОУ ВО «Ульяновский государственный технический университет»

432027 Россия, г. Ульяновск, ул. Северный Венец, 32

E-mail:kroshneva@yandex.ru

\section{M.E. Kroshneva \\ PUBLISHING HOUSE, “EXCELLENTLY PUBLISHING WORTHY BOOKS...”}

DOI: $10.35634 / 2412-9534-2021-31-3-564-570$

The paper explores the actual features of the historical and literary context of book culture in Finland in Russian. On the example of the publishing house "Biblion" (1919-1921) the information is provided that contributes to the study of the publishing activities of foreign organizations, subjects of Sweden and Finland, contributing to the appearance of books of fiction by many Russian authors, the most famous of which during this period were Leonid Andreev and Alexander Kuprin. For a more complete presentation of the issue of the development of Russian book publishing between 1919 and 1921, it is necessary to know not only about trends on a national scale, to see the features of the development of book publishing in the regions, but also to take into account the specifics of the work of publishing houses and publishing activities of Russian abroad. The relevance of the issue is confirmed by the lack of domestic studies on the topic of publishing Russian literature abroad.

The results of the work can be used in teaching courses on literature and culture of the Russian abroad countries, the history of Russian literature of the $1 / 3$ of the XX century, studies of regional literature, with the refinement and addition of biobibliographies, bibliographies, catalogs, encyclopedias, other publications of Russian literature abroad.

Keywords: publishing, Russian abroad, Russian literature.

\section{REFERENCES}

1. Andreev L.N. Dnevnik Satany [Diary of Satan] // Kostry [Bonfires]. Moscow: Gosizdat Publ., 1922. Kn. 1: (v sokrashch) [Book 1]. (In Russian).

2. Dinnershtejn E.A. K voprosu o reputacii izdatelya Z. Grzhebina [On the issue of the reputation of the publisher Z. Grzhebin]. URL: https://magazines.gorky.media/nlo/2010/6/k-voprosu-o-reputaczii-izdatelya-z-grzhebina.html (In Russian).

3. Fal'kovskij F. Dnevnik Satany Leonida Andreeva [Diary of Satan Leonid Andreev] // Put'. 1921. 8 marta. S. 2-3 [Way. 1921. 8 March. P. 2-3]; Tukalevskij V. Leonid Andreev. Dnevnik Satany [Diary of Satan Leonid Andreev] // Russkaya kniga. 1921. №3. S. 21 [Russian book. 1921. No. 3. P. 21]. (In Russian).

4. Hellman B., Chellberg Yu. Bibliografiya russkoj literatury, izdannoj v Finlyandii 1813-1971 [Bibliography of Russian literature published in Finland 1813-1971]. Helsinki ylohiston kirjasto. Helsinki, 1988. (In Russian).

5. Hellman B. «My - Serapionovy brat'ya» ["We are the Serapion brothers"]// Serapionovy brat'ya. 1921: al'manah. SPb.: Izdatel'stvo K. Tublina [The Serapion brothers. 1921: almanac. SPb.: Publishing house of K.Tublin]. 75 s. [Elektronnyj resurs]. URL : https://litlife.club/books/260747/read?page=3 (In Russian).

6. Hellman B. Biblion. A Russian Publishing House in Finland // Studia Slavica Finlandensia. Helsinki. 1985. II. S. 1-48. (In English).

Kroshneva M.E., Candidate of Philology, Associate Professor at Department of Philology,

Media Technologies and Graphic Design

Ulyanovsk State Technical University

Severnyi Venets st., 32, Ulyanovsk, Russia, 432027

E-mail:kroshneva@yandex.ru 